\title{
EFEKTIVITAS PSIKOEDUKASI DAN FAMILY CENTERED MATERNITY CARE PADA IBU POSTPARTUM
}

\section{THE EFFECTIVENESS OF PSYCHOEDUCATION AND FAMILY CENTERED MATERNITY CARE IN MATERNAL POSTPARTUM}

\author{
Adenia Dwi Ristanti ${ }^{1}$, Elly Dwi Masita ${ }^{2}$ \\ Fakultas Keperawatan dan Kebidanan, Universitas Nahdlatul Ulama Surabaya \\ (email korespondensi: adeniadr@unusa.ac.id) \\ Info Artikel: Diterima: 09 September 2020 Revisi: 10 Oktober 2020 Disetujui: 15 Desember 2020
}

\begin{abstract}
ABSTRAK
Latar Belakang: Periode masa nifas yang dialami ibu postpartum masih memiliki beberapa kendala salah satunya persepsi yang belum sinergis dengan anjuran kesehatan. Paradigma pemulihan ibu postpartum yang baru menekankan bahwa ibu postpartum merupakan peristiwa fisiologis sehingga prinsip perawatannya hanya berorientasi pada kemandirian ibu postpartum tersebut. Penelitian ini bertujuan untuk membuktikan efektifitas psikoedukasi dan family centered maternity care (FCMC) pada ibu postpartum.

Metode: Penelitian ini merupakan penelitian quasy experiment rancangan pretest-posttest control group desaign. Sampel pada penelitian ini $40 \mathrm{ibu}$ postpartum dengan teknik pengambilan sampel non random sampling. Uji statistik menggunakan independent T test.

Hasil: Hasil analisis dengan Independent $\mathrm{t}$ test diperoleh mean pada kelompok intervensi

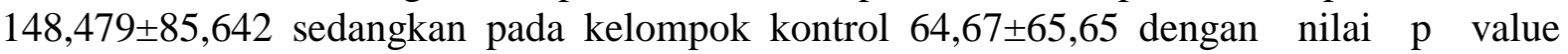
0,009 .
\end{abstract}

Kesimpulan: Maka dapat diasumsikan bahwa ada peningkatan yang bermakna setelah perlakuan sehingga ada pengaruh peningkatan pemberian psikoedukasi dan Family Centered Maternity Care (FCMC) sebelum dan setelah perlakuan.

Kata kunci : Psikoedukasi, FCMC, Postpartum

\section{ABSTRACT}

Background: The postpartum period experienced by postpartum mothers still has several obstacles, one of which is the perception that is not synergistic with health recommendations. The new postpartum mother recovery paradigm emphasizes that postpartum mother is a physiological event so that the principle of care is only oriented to the independence of the postpartum mother. This study aims to prove the effectiveness of psychoeducation and family centered maternity care (FCMC) in postpartum mothers.

Methods: This study used a quasy experiment with a design pretest-posttest control group desaign. The sample was 40 postpartum mothers with non-random sampling technique. Statistical test using the independent $T$ test.

Results: The results of the analysis with the Independent $t$ test obtained a mean in the intervention group $148.479 \pm 85.642$ while in the control group $64.67 \pm 65.65$ with a p value of 0.009.

Conclusion: So it can be assumed that there is a significant increase after treatment so that there is an effect of increasing the provision of psychoeducation and Family Centered Maternity Care (FCMC) before and after treatment.

Keywords : Psychoeducation, FCMC, Postpartum 


\section{PENDAHULUAN}

Masa Nifas merupakan waktu pemulihan organ reproduksi pada keadaan sebelum hamil yang berlangsung pada saat persalinan sampai 6 minggu postpartum. Periode masa nifas memiliki beberapa kendala salah satunya yaitu persepsi yang belum sinergis dengan anjuran kesehatan ${ }^{1}$. Paradigma pemulihan menekankan ibu postpartum merupakan peristiwa normal atau fisiologis sehingga prinsip perawatannya hanya berorientasi pada individu ibu masingmasing ${ }^{2}$. Masa postpartum masa cukup penting bagi tenaga kesehatan untuk melakukan pemantauan, sebab pelaksanaan yang kurang optimal dapat menambah AKI seperti komplikasi, hipertensi, serta perdarahan post partum. ${ }^{3}$

WHO menyatakan 500.000 AKI setiap tahun diakibatkan oleh komplikasi pada kehamilan serta melahirkan, sebagian besar AKI terjadi selama atau segera setelah melahirkan ${ }^{4}$. Indonesia merupakan salah satu negara berkembang dengan masalah kesehatan yang menjadi perhatian khusus adalah Angka Kematian Ibu yang tergolong tinggi. Untuk menanggulangi AKI yang tergolong masih tinggi pemerintah mencanangkan program Sustainable Development Goals (SDGs) target ke 5 menurunkan AKI, akan tetapi program tersebut masih belum efektif. 5 penyebab angka kematian ibu terbesar yaitu perdarahan, hipertensi dalam kehamilan, infeksi, partus lama/ partus macet serta abortus. Kematian ibu di Indonesia didominasi oleh 3 penyebab utama terdiri dari perdarahan, hipertensi dalam kehamilan, serta infeksi. Masa postpartum umumnya terjadi banyak masalah yang menyertai ibu, diantaranya proses menyusui, kemandirian ibu merawat bayi, nyeri jahitan, perawatan luka jahitan, kebersihan, istirahat dan kaki bengkak, sehingga menimbulkan ketidaknyamanan ibu dalam melalui masa nifas ${ }^{5}$. Untuk itu yang perlu perhatian adalah mengidentifikasi masalah kesehatan ibu selama masa postpartum salah satunya yaitu masa nifas,

\section{METODE}

Jenis penelitian merupakan penelitian Quasy Experiment dengan desain pretestposttest control grup design. Jumlah sampel sebanyak 40 responden terdiri dari ibu post partum masing-masing 20 kelompok intervensi termasuk bayi yang menjadi tanggung jawab ibu sebagai orangtua. ${ }^{6}$

Cara untuk meningkatkan pengetahuan serta perilaku kesehatan salah satunya yaitu memberikan pendidikan kesehatan serta psikoedukasi, sehingga timbul kesadaran individu/masyarakat agar berperilaku sesuai dengan pengetahuan yang dimilikinya ${ }^{7}$. Pendidikan kesehatan adalah upaya untuk mempengaruhi orang lain, individu, kelompok/masyarakat untuk memelihara serta meningkatkan kesehatan. Hasil yang diperoleh dari promosi/pendidikan kesehatan yaitu perilaku kesehatan/perilaku memelihara serta meningkatkan kesehatan yang kondusif oleh sasaran promosi Kesehatan ${ }^{8}$.

Salah satu informasi kesehatan yang dibutuhkan pada masa postpartum adalah pemberian metode psikoedukasi serta Family Centered Maternity Care (FCMC). Psikoedukasi adalah usaha yang dilakukan sebagai peningkatan pemahaman kepada orang lain yang sedang mengalami gangguan psikologis. Family Centered Maternity Care (FCMC) merupakan perawatan berpusat pada keluarga yaitu dengan menyediakan perawatan bagi wanita serta keluarga mereka yang mengintegrasikan kehamilan, persalinan, nifas, serta perawatan bayi baru lahir kedalam kontinum siklus kehidupan keluarga dengan cara hidup sehat. Perawatan yang akan diberikan kepada individual mengutamakan dukungan, partisipasi, serta pilihan dari keluarga .

Adapun tujuan dari penelitian ini adalah mengetahui efektifitas psikoedukasi dan family centered maternity care (FCMC) pada ibu postpartum. Penelitian ini penting, sebab masih sedikit penelitian di Indonesia yang mengungkapnya mengingat jumlah kendala. Belum adanya data yang menunjukkan efektifitas psikoedukasi dan family centered maternity care (FCMC) pada ibu postpartum.

dan kelompok kontrol. Data dikumpulkan menggunakan kuesioner dan analisis data dilakukan secara univariat dan bivaiat menggunakan uji Wilcoxon. 
Pada kelompok perlakuan dilakukan home care sebanyak $3 \mathrm{x}$ sesi pada hari ke 4,10 dan 14 selama 14 hari. Instrumen yang digunakan yaitu leaflet dan kuesioner. Kriteria sampel adalah ibu postpartum fisiologis, dapat berkomunikasi dengan baik dan mendapat dukungan keluarga.

\section{HASIL}

Tabel 1. Distribusi Karakteristik Responden $(n=40)$

\begin{tabular}{|c|c|c|c|c|c|}
\hline \multirow[t]{2}{*}{ Karakteristik } & \multicolumn{2}{|c|}{$\begin{array}{c}\text { Kelompok } \\
\text { Intervensi }(n=20)\end{array}$} & \multicolumn{2}{|c|}{ Kelompok Kontrol $(\mathrm{n}=20)$} & \multirow[t]{2}{*}{ *pvalue } \\
\hline & Jumlah & $\%$ & Jumlah & $\%$ & \\
\hline Umur (mean \pm SD) & $31,00 \pm 7,062$ & & $36,69 \pm 4,254$ & & 0,364 \\
\hline Min-Max & $18-42$ & & $19-42$ & & \\
\hline$<20$ tahum & 5 & 25 & 4 & 20 & \\
\hline 21-35 tahun & 9 & 45 & 9 & 45 & \\
\hline$>35$ tahun & 6 & 30 & 7 & 35 & \\
\hline Paritas & & & & & 0,505 \\
\hline Primipara & 8 & 40 & 9 & 45 & \\
\hline Multipara & 4 & 20 & 3 & 15 & \\
\hline Grandemultipara & 8 & 40 & 8 & 40 & \\
\hline Pendidikan & & & & & 0,550 \\
\hline Dasar & 5 & 25 & 6 & 30 & \\
\hline Menengah & 12 & 60 & 9 & 45 & \\
\hline Atas & 3 & 15 & 5 & 25 & \\
\hline Jenis Persalinan & & & & & 0,682 \\
\hline Normal & 13 & 65 & 11 & 55 & \\
\hline SC & 7 & 35 & 9 & 45 & \\
\hline \multicolumn{6}{|l|}{ Riwayat Persalinan } \\
\hline Komplikasi & 9 & 45 & 5 & 25 & 0,540 \\
\hline Tidak Komplikasi & 11 & 55 & 15 & 75 & \\
\hline \multicolumn{6}{|c|}{ Riwayat Nifas yang Lalu } \\
\hline Komplikasi & 13 & 65 & 9 & 45 & 1,00 \\
\hline Tidak ada komplikasi & 7 & 35 & 11 & 55 & \\
\hline Pekerjaan & & & & & 0,816 \\
\hline Bekerja & 8 & 40 & 9 & 45 & \\
\hline Tidak bekerja & 12 & 60 & 11 & 55 & \\
\hline
\end{tabular}

Dari Tabel 1 diatas menunjukkan uji homogenitas karakteristik awal pada kedua kelompok kontrol dan kelompok intervensi pada variabel usia, paritas, pendidikan, jenis persalinan, riwayat persalinan, riwayat nifas yang lalu, dan pekerjaan kedua kelompok menunjukkan nilai $p>0,05$ yaitu variabel tersebut memiliki sebaran data yang homogen.

Tabel 2. Efektivitas Psikoedukasi Pada Ibu Postpartum

\begin{tabular}{lccc}
\hline Psikoedukasi & Pre & Post & \multirow{2}{*}{ P value } \\
\cline { 2 - 3 } & Mean \pm SD & Mean \pm SD & \\
\hline Intervensi & $10,29 \pm 0,480$ & $8,92 \pm 0,738$ & $0,000^{\mathrm{b}}$ \\
Kontrol & $10,57 \pm 0,524$ & $9,86 \pm 0,841$ & $0,000^{\mathrm{b}}$ \\
$\Delta$ & $-1,480 \pm 0,727$ & $-0,81 \pm 0,859$ & $0,004^{\mathrm{a}}$ \\
\hline \multicolumn{2}{l}{${\text { Mann } \text { Whitney }^{a} \text { Wilcoxon }^{b} \text { Test }}^{\text {Tyyn}}$} & &
\end{tabular}


Berdasarkan tabel diatas didapatkan rerata psikoedukasi pada kelompok intervensi sebelum dilakukan perlakuan 10,29 $\pm 0,480$ sedangkan setelah perlakuan 8,92 $\pm 0,738$. Pada kelompok kontrol sebelum dilakukan perlakuan $10,57 \pm 0,524$, dan setelah dilakukan perlakuan $\quad 9,86 \pm 0,841$.Hasil analisis psikoedukasi sebelum dan setelah perlakuan pada kelompok intervensi dengan Mann
Withney pada kelompok intervensi $1,480 \pm 0,727$ sedangkan pada kelompok kontrol $-0,81 \pm 0,859$ dan diperoleh nilai $\mathrm{p}$ value 0,004 dapat diartikan ada peningkatan pemberian psikoedukasi bermakna setelah perlakuan sehingga ada pengaruh pemberian Psikoedukasi teradap ibu postpartum sebelum dan setelah perlakuan.

Tabel 3. Efektivitas Psikoedukasi dan Family Centered Maternity Care (FCMC) Pada Ibu Postpartum (n=40)

\begin{tabular}{|c|c|c|c|}
\hline Psikoedukasi dan Family & Pre & Post & P value \\
\hline $\begin{array}{l}\text { Centered Maternity Care } \\
\text { (FCMC) }\end{array}$ & Mean \pm SD & Mean \pm SD & \\
\hline Intervensi & $332,88 \pm 84,088$ & $194,59 \pm 68,760$ & $0,000^{\mathrm{b}}$ \\
\hline Kontrol & $332,15 \pm 98,166$ & $267,57 \pm 64,37$ & $0,000^{\mathrm{b}}$ \\
\hline$\Delta$ & $148,479 \pm 85,642$ & $64,67 \pm 65,65$ & $0,009^{\mathrm{a}}$ \\
\hline
\end{tabular}

Berdasarkan tabel diatas didatapatkan rerata pemberian Psikoedukasi dan Family Centered Maternity Care (FCMC) pada kelompok intervensi sebelum dilakukan perlakuan $332,88 \pm 84,088$ sedangkan setelah perlakuan 194,59 $\pm 68,760$. Pada kelompok kontrol sebelum dilakukan perlakuan $332,15 \pm 98,166$ dan setelah dilakukan perlakuan 267,57 $\pm 64,37$. Hasil analisis pemberian Psikoedukasi dan Family Centered Maternity Care (FCMC) sebelum dan setelah perlakuan

\section{PEMBAHASAN}

Masa postpartum merupakan pengalaman yang akan dialami oleh perempuan yang baru saja melahirkan terutama pada wanita yang pertama kali melahirkan. Pada perkembangan kondisi ini perempuan sering mengalami peningkatan serta perubahan emosi psikologis dikarenakan oleh beberapa faktor antara lain adanya penyesuaian di lingkungan baru, harapan sosial agar berperilaku lebih baik, masalah di sekolah/pekerjaan, serta hubungan keluarga yang tidak harmonis, akan menyebabkan ibu usia muda untuk bisa beradaptasi dengan kehidupan barunya ${ }^{10}$.

Perubahan peran wanita memerlukan adaptasi yang wajib dilakukan yaitu perubahan emosi serta sosial ${ }^{11}$. Adaptasi psikologis tersebut menjadi periode kerentanan pada wanita yang baru saja melahirkan, sebab periode ini membutuhkan peran professional pada kelompok intervensi dengan Independent $\mathrm{t}$ test diperoleh mean pada kelompok intervensi 148,479 $\pm 85,642$

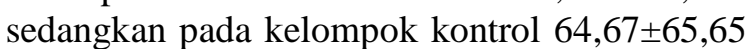
dengan nilai $p$ value 0,009 artinya terdapat peningkatan yang bermakna setelah perlakuan sehingga ada pengaruh peningkatan pemberian psikoedukasi dan Family Centered Maternity Care (FCMC) sebelum dan setelah perlakuan.

kesehatan serta keluarga. Tanggung jawab wanita bertambah dengan kehadiran bayi baru lahir ${ }^{12}$. Ikatan ibu dan bayi sudah lama terbentuk sebelum kelahiran hal tersebut akan semakin mendorong wanita untuk menjadi ibu yang sesungguhnya. Oleh sebab itu pentingnya psikoedukasi dan Family Centered Maternity Care pada ibu postpartum supaya ibu dapat dengan mudah menumbuhkan rasa kasih sayang kepada bayinya tidak hanya melalui fisik seperti menyusui, merawat tali pusat, mengganti popok tetapi juga dari psikologis seperti menimang, mencium, serta menatap agar kasih sayang ibu dapat terus terjaga ${ }^{13}$.

Psikoedukasi merupakan suatu tindakan yang untuk memperkuat strategi koping yang diberikan kepada individu dan keluarga. Psikoedukasi dapat diberikan pada individu atau kelompok dan dapat dilaksanakan 
diberbagai tempat ${ }^{14}$. Tindakan psikoedukasi memiliki media berupa catatan seperti video, booklet, poster, serta beberapa eksplorasi yang dibutuhkan. Sebagai kunci keberhasilan intervensi maka diperlukan kehadiran keluarga atau Family Centered Maternity Care $(\mathrm{FCMC})^{15}$.

Untuk mencegah terjadinya gangguan emosional pada masa postpartum dapat menggunakan startegi koping yang efektif, psikoedukasi dan Family Centered Maternity Care (FCMC) dapat memberikan keuntungan bagi mereka dengan cara bidan membangun hubungan saling percaya ${ }^{16}$. Psikoedukasi dan Family Centered Maternity Care (FCMC) merupakan tindakan yang ditujukan untuk memperbaiki serta meningkatkan respons positif ibu dan suaminya sesuai yang diharapkan difokuskan pada mempertahankan self oncept needs, perubahan fungsi/peran serta ketergantungan/kebutuhan interaksi ${ }^{17}$.

Pemberian psikoedukasi dan Family Centered Maternity Care (FCMC) pada penggunaan koping yang tepat dapat membantu mengurangi kecemasan serta mengurangi depresi, perasaan menjadi jauh lebih baik serta bisa membantu memecahkan masalah yang sedang dihadapi, dan dapat menumbuhkan rasa percaya diri ${ }^{18}$. Penggunaan koping dipengaruhi karakteristik

\section{KESIMPULAN DAN SARAN}

Berdasarkan hasil penelitian terdapat peningkatan yang bermakna setelah intervensi pemberian psikoedukasi dan Family Centered Maternity Care (FCMC) sebelum dan setelah perlakuan.

Diharapkan ibu postpartum mampu menyesuikan diri terhadap perubahan setelah

\section{UCAPAN TERIMA KASIH}

Tim penulis mengucapkan terima kasih kepada Lembaga Penelitian dan Pengabdian dari orang tersebut yaitu: 1) usia, orang lebih tua berusaha untuk menjadi model orang yang lebih muda, semakin tinggi usia diharapkan lebih mampu menyesuaikan diri pada suatu masalah; 2) pengalaman, ibu multigravida mempunyaii pengalaman mengasuh serta merawat anak, sehingga mampu mengatasi masalah yang timbul. Sedangkan ibu dengan primipara harus beradaptasi dan membutuhkan waktu pada perubahan peran menjadi ibu; 3) paritas, riwayat kehamilan sampai bersalin dan komplikasi kehamilan dan persalinan sebelumnya. Serta jumlah anak yang dilahirkan mempengaruhi koping dalam menghadapi stres; 4) tingkat pendidikan, orang berpendidikan tinggi lebih realistis serta lebih aktif memecahkan masalah dibandingkan dengan orang yang berpendidikan rendah; 5) pekerjaan, memiliki status pekerjaan mampu melakukan analisis logis untuk mengatasi masalah, sedangkan yang tidak memiliki status pekerjaan cenderung menggunakan strategi berbentuk pelepasan emosi serta menghindari masalah; 6) dukungan suami, pada ibu bersalin yang didampingi suaminya pada saat melahirkan akan merasa mendapatkan dukungan yang lebih serta dapat menurunkan tingkat stres dalam melalui proses persalinan $^{19}$.

persalinan, mampu mengendalikan emosi dan terbuka dengan keluarga agar ibu merasa tenang dan mendapatkan perhatian dari keluarga, sehingga ibu dapat terbantu dalam menyelesaikan kegiatan rumah tangganya dan mengurusi bayinya.

Masyarakat Universitas Nahdlatul Ulama Surabaya yang telah mendanai penelitian ini. 


\section{DAFTAR PUSTAKA}

1. Shi X, Ying Y, Yu Z, Zhu J, Feng W, Xu $\mathrm{D}$, et al. Risk factors for postpartum depression in Chinese women: A crosssectional study at 6 weeks postpartum. J Psychosom Res [Internet]. 2020;110295. Available from: http://www.sciencedirect.com/science/artic le/pii/S0022399920308576

2. Poreddi V, Thomas B, Paulose B, Jose B, Daniel BM, Somagattu SNR, et al. Knowledge and attitudes of family members towards postpartum depression. Arch Psychiatr Nurs [Internet]. 2020; Available from: http://www.sciencedirect.com/science/artic le/pii/S0883941720305343

3. Baskin R, Galligan R, Meyer D. Disordered eating from pregnancy to the postpartum period: The role of psychosocial and mental health factors. Appetite [Internet]. 2021;156:104862. Available from: http://www.sciencedirect.com/science/artic le/pii/S0195666320306127

4. World Health Organization. World Health Statistics 2018. 2018th ed. Switzerland: WHO; 2018.

5. Kesehatan K, Indonesia R. PROFIL KESEHATAN INDONESIA TAHUN 2017. Kementrian Kesehatan Indonesia, editor. Jakarta: Kementrian Kesehatan Indonesia; 2017.

6. Ntow KO, Krzeczkowski JE, Amani B, Savoy CD, Schmidt LA, Van Lieshout RJ. Maternal and Infant Performance on the Face-to-Face Still-Face Task following Maternal Cognitive Behavioral Therapy for Postpartum Depression. J Affect Disord [Internet]. 2021;278:583-91. Available from:

http://www.sciencedirect.com/science/artic le/pii/S016503272032797X

7. Farzan SF, Howe CG, Chen Y, GilbertDiamond D, Korrick S, Jackson BP, et al. Prenatal and postnatal mercury exposure and blood pressure in childhood. Environ Int [Internet]. 2021;146:106201. Available from:

http://www.sciencedirect.com/science/artic le/pii/S0160412020321565

8. Bienertova-Vasku J. Chapter 4 - Maternal undernutrition and antenatal and postnatal growth trajectories-Epidemiology and pathophysiology. In: Vinciguerra M, Sanchez PCBT-MNM and I, editors. Academic Press; 2021. p. 87-105. Available from: http://www.sciencedirect.com/science/artic le/pii/B9780128138625000049

9. Szajewska H. Chapter 13 - Clinical data from postnatal interventions. In: Koren $\mathrm{O}$, Rautava SBT-THM in EL, editors. Academic Press; 2021. p. 287-99. Available from: http://www.sciencedirect.com/science/artic le/pii/B9780128180976000134

10. de la Garza AL, Treviño-de Alba C, Cárdenas-Pérez RE, Camacho A, Gutierrez-Lopez M, Castro H. Chapter 6 Fatty acid intake during perinatal periods. In: Vinciguerra M, Sanchez PCBT-MNM and I, editors. Academic Press; 2021. p. 135-54. Available from: http://www.sciencedirect.com/science/artic le/pii/B9780128138625000062

11. Vogels-Broeke M, de Vries PR, Nieuwenhuijze M. Validating a framework of women's experience of the perinatal period; a scoping review. Midwifery [Internet]. 2021;92:102866. Available from:

http://www.sciencedirect.com/science/artic le/pii/S0266613820302382

12. Kahalon R, Preis H, Benyamini Y. Who benefits most from skin-to-skin motherinfant contact after birth? Survey findings on skin-to-skin and birth satisfaction by mode of birth. Midwifery [Internet]. 2021;92:102862. Available from: http://www.sciencedirect.com/science/artic le/pii/S0266613820302345

13. Kuroda Y, Goto A, Koyama Y, Hosoya M, Fujimori K, Yasumura S, et al. Antenatal and postnatal association of maternal bonding and mental health in Fukushima after the Great East Japan Earthquake of 2011:The Japan Environment and Children's Study (JECS). J Affect Disord [Internet]. 2021;278:244-51. Available from:

http://www.sciencedirect.com/science/artic le/pii/S0165032720327166

14. Church L. Quiet Time During Postpartum Hospitalization Can Improve Rest, 
Bonding, and Breastfeeding. Nurs Womens Health [Internet]. 2020;24(3):197-201. Available from: http://www.sciencedirect.com/science/artic le/pii/S1751485120300611

15. Trisnayuni R, Suriah, Masni. The effect of leaflet giving on postpartum care in pregnant women in the area of Katobengke Health Center, Baubau City in 2019. Enfermería Clínica [Internet]. 2020;30:333-6. Available from: http://www.sciencedirect.com/science/artic le/pii/S1130862120302114

16. Szafrańska M, Begley C, Carroll M, Daly D. Factors associated with maternal readmission to hospital, attendance at emergency rooms or visits to general practitioners within three months postpartum. Eur J Obstet Gynecol Reprod Biol [Internet]. 2020;254:251-8. Available from:

http://www.sciencedirect.com/science/artic
le/pii/S0301211520305947

17. Huang L-H, Lee T-H, Huang J-Y, Ng S-C, Lee M-S, Lee S-H. Effect of stay in a postpartum care institution on postpartum depression in women. Midwifery [Internet]. 2020;82:102600. Available from:

http://www.sciencedirect.com/science/artic le/pii/S0266613819302918

18. Beecher C, Drummond L, Foley C, White M, Greene R, Ryan E, et al. Development of a survey instrument to evaluate women's experiences of their maternity care. Women and Birth [Internet]. 2020; Available from: http://www.sciencedirect.com/science/artic le/pii/S1871519220302857

19. Zappas MP, Becker K, Walton-Moss B. Postpartum Anxiety. J Nurse Pract [Internet]. 2020; Available from: http://www.sciencedirect.com/science/artic le/pii/S1555415520304529 